\title{
TECNOLOGIAS SUSTENTÁVEIS COMO SOLUÇÃO AOS IMPACTOS DA EXPANSÃO URBANA: ENERGIA SOLAR E TELHADO VERDE
}

\author{
SUSTAINABLE TECHNOLOGIES AS A SOLUTION FOR URBAN EXPANSION IMPACTS: \\ SOLAR ENERGY AND GREEN ROOF
}

\author{
TECNOLOGÍAS SUSTENTABLES COMO SOLUCIÓN PARA LOS IMPACTOS DE LA \\ EXPANSIÓN URBANA: ENERGÍA SOLAR Y TECHOS VERDES
}

\author{
Felipe Torres dos Santos ${ }^{1}$ \\ Rafael Lopes Ferreira ${ }^{2}$
}

\begin{abstract}
Resumo
O crescimento dos centros urbanos impactou diretamente o meio ambiente. Assim, questões como impermeabilização do solo e emissão de gases do efeito estufa são exemplos dos fenômenos causados pela urbanização desenfreada e sem planejamento. Esses fenômenos convergiram para problemas cotidianos da vida urbana, o que torna necessária a otimização da relação entre cidade e meio ambiente. O presente estudo analisa as questões técnicas de duas tecnologias, o telhado verde e a energia solar fotovoltaica; logo, essas tecnologias têm relação direta com o desenvolvimento sustentável das cidades. Realizou-se, como metodologia, a elaboração de indicadores que levou em consideração aspectos sociais, ambientais e econômicos. Esses indicadores deram origem a um sistema de pontuação e, a partir desse sistema, avaliou-se a viabilidade das tecnologias supracitadas, fundamentadas teoricamente. Concluiu-se que a energia solar é moderadamente viável para utilização na construção sustentável e o telhado verde viável; contudo, para a segunda tecnologia, considerou-se a implantação sem necessidade de reforço estrutural, o que diminuiu os custos da instalação e afetou o indicador econômico.
\end{abstract}

Palavras-chave: Construções sustentáveis. Telhado verde. Energia solar. Cidades sustentáveis.

\begin{abstract}
The growth of urban centers has directly impacted the environment. Thus, issues such as soil waterproofing and greenhouse gas emissions are examples of the phenomena caused by unbridled urbanization and without planning. These phenomena converged to everyday problems of urban life, which makes it necessary to optimize the relationship between city and environment. This study analyzes the technical issues of two technologies, the green roof and photovoltaic solar energy; therefore, these technologies are directly related to the sustainable development of cities. The methodology was developed by indicators that considered social, environmental and economic aspects. These indicators gave rise to a scoring system and, from this system, the feasibility of the technologies, theoretically based, was evaluated. It was concluded that solar energy is moderately viable for use in sustainable construction, while the green roof viable; however, for the second technology, the implementation was considered without the need for structural reinforcement, which decreased the costs of the installation and impacted the economic indicator.
\end{abstract}

Keywords: Sustainable construction. Green roof. Solar energy. Sustainable cities.

\section{Resumen}

El crecimiento de los centros urbanos ha producido impacto directo sobre el medio ambiente. De esa manera, cuestiones como la impermeabilización del suelo y emisiones de gases con efecto estufa son ejemplos de los fenómenos causados por la urbanización desenfrenada y sin planificación. Esos fenómenos condujeron a la

\footnotetext{
1 Especialista em Gestão Ambiental e Desenvolvimento Sustentável (UNINTER - 2019). E-mail: felipe.torresantos@gmail.com.

${ }^{2}$ Mestre em Ciência e Tecnologia Ambiental (UTFPR). E-mail: raffer@alunos.utfpr.edu.br.
} 
generación de problemas urbanos, lo que hace necesaria la optimización de la relación entre ciudad y medio ambiente. Este estudio presenta las cuestiones técnicas de dos tecnologías, el techo verde y la energía solar fotovoltaica, por su relación directa con el desarrollo sostenible de las ciudades. Como metodología, se elaboraron indicadores asociados a aspectos sociales, ambientales y económicos. Ellos dieron origen a un sistema de puntaje y, a partir de él, se evaluó la viabilidad de las tecnologías citadas arriba, con la debida fundamentación teórica. Se pudo constatar que la utilización de la energía solar en la construcción sustentable es moderadamente viable, mientras que la de los techos verdes es viable. Sin embargo, en la aplicación de la segunda tecnología en cuestión, no se consideró la necesidad de refuerzo estructural, lo que disminuye los costos de instalación e incide sobre el indicador económico.

Palabras-clave: Construcciones sustentables. Techos verdes. Energía solar. Ciudades sustentables.

\section{Introdução}

O desenvolvimento da humanidade ocorreu em detrimento aos recursos naturais. A Mesopotâmia, por exemplo, uma das primeiras civilizações existentes, teve seu êxito graças ao desenvolvimento de um sistema hidráulico complexo, o que demandou uma série de modificações no ambiente, drenando pântanos e construindo barragens e diques ainda no ano de 4.000 A.C (VICENTINO; DORIGO, 2007).

Assim, os centros urbanos surgiram como necessidade ao aumento populacional e, de acordo com a ONU, a população mundial irá aumentar substancialmente até o ano de 2050 (PRIZIBISCZKI, 2013).

Espera-se que a sociedade desenvolva tecnologias e hábitos que promovam o uso sustentável dos recursos naturais e mitiguem o impacto ambiental como um todo, de forma a garantir a sobrevivência das gerações futuras - o que é premissa da gestão ambiental.

São diversas as tecnologias desenvolvidas com foco no desenvolvimento sustentável, com o intuito de associar o crescimento social/econômico com a conservação ambiental.

Partindo desta premissa, o presente estudo analisou duas dessas tecnologias. Essas tecnologias foram explanadas, além de se investigar, na pesquisa, a viabilidade econômica, social e ambiental delas no cenário brasileiro e desmistificar fatores vinculados ao senso comum.

\section{Breve histórico da relação meio ambiente e expansão urbana}

Pode-se entender que a expansão dos centros urbanos está diretamente vinculada ao progresso do capital e ao aumento populacional. A Revolução Industrial pode ser considerada um marco histórico neste sentido, visto o desenvolvimento econômico proveniente dos processos fabris — onde surgiram novas fontes de poluição do ar, a partir do desenvolvimento de motores à combustão e de siderúrgicas (CANÇADO et al., 2006). 
Não houve o devido acompanhamento e avaliação dos impactos destes processos ao meio ambiente. Assim, uma série de eventos relacionados à elevação da concentração de poluentes do ar causaram diversas mortes, como por exemplo o episódio do great smog (grande nevoeiro) de 1952 em Londres.

Apesar dos eventos históricos, a preocupação ambiental internacional se efetivou apenas em meados da década de 1960, com o lançamento do livro Primavera Silenciosa de Rachel Carson. Em 1972, a ONU iniciou as tentativas de melhoria das relações homemmeio ambiente com a Conferência de Estocolmo.

Apesar dos objetivos ambiciosos dos acordos e encontros, Vormittag, Saldiva e Miranda (2013) afirmam que a poluição atmosférica foi responsável pela morte de 2 milhões de pessoas no mundo em 2011, além de uma redução de 1,5 ano na expectativa de vida em São Paulo - decorrente do impacto da poluição.

Tem-se a falsa impressão de que o crescimento urbano se deu exclusivamente em países desenvolvidos; contudo, Davis (2006) demonstra que o crescimento em países ditos subdesenvolvidos foi superior ao de países mais ricos, graças a valorização do capital financeiro e a falta de investimento no pequeno e médio agricultor. Isso ocasionou a "expulsão" desses agricultores para os centros urbanos, em busca de oportunidades e melhoria da qualidade de vida.

No Brasil, o fenômeno da transição demográfica, que é caracterizado pelo momento em que a população urbana ultrapassa a população rural, se deu por volta da década de 60 (ONU,2018). Vasconcelos e Gomes (2012) destacam que essa transição ocorreu devido à maior acessibilidade das famílias brasileiras aos programas de Saúde Pública e saneamento básico.

Com o aumento da população urbana, surge a necessidade de se disponibilizar habitação, necessidade considerada direito fundamental e prevista no artigo $6^{\circ}$ da Constituição Federal do Brasil (BRASIL, 1988).

Este direito é fundamentado pelo Planejamento Urbano que dispõe de uma série de ferramentas e estratégias que buscam otimizar o uso do espaço em consonância com a mitigação dos impactos ambientais e sociais negativos (BRASIL, 1988).

Apesar dos municípios prezarem pelo devido Planejamento Urbano, através dos seus Planos Diretores e Zoneamentos Ecológico Econômicos, uma série de contrariedades surgiram graças ao processo de expansão de cidades, como: a impermeabilização do solo, formação de ilhas de calor e poluição atmosférica; com isso, a preocupação com a sustentabilidade no meio urbano se tornou uma necessidade. 
Na Conferência RIO 92, a expressão "construções sustentáveis" ganhou notoriedade, fundamentadas no princípio do desenvolvimento sustentável, cunhado anteriormente na Conferência de Estocolmo (1972). A premissa do conceito é de aliar o crescimento econômico, o bem-estar social e a conservação ambiental (MATEUS, 2009), satisfazer as necessidades presentes e não comprometer as gerações futuras.

A legislação brasileira acompanhou esta tendência e incluiu no Estatuto das Cidades (Lei $\left.\mathrm{n}^{\circ} 10.257 / 01\right)$, em seu inciso I do artigo $2^{\circ}$, o seguinte texto:

Garantia do direito a cidades sustentáveis, entendido como o direito à terra urbana, à moradia, ao saneamento ambiental, à infraestrutura urbana, ao transporte e aos serviços públicos, ao trabalho e ao lazer, para as presentes e futuras gerações (BRASIL, 2001).

Kibert (1994) conceitua construções sustentáveis como a criação e manutenção de um ambiente construído, baseado na utilização eficiente de recursos e em princípios ecológicos. Assim, o autor aponta como alternativas de construções sustentáveis a redução do consumo energético e de água (CORRÊA, 2009).

Das diversas tecnologias existentes no meio da construção civil, este trabalho explorará o telhado verde e o sistema de energia fotovoltaica, ambos amplamente difundidos por profissionais destas áreas.

Os pontos positivos destas tendências são inúmeros; contudo, por falta de conhecimento, muitos consumidores desconsideram essas tecnologias devido às informações difundidas no senso comum.

Desta maneira, são necessários incentivos para instigar empreendedores e cidadãos a utilizarem essas tecnologias no processo de construção de seus empreendimentos e residências.

Desta forma, cita-se como incentivo a certificação LEED que é oferecida a construções e empreendimentos que assumam a responsabilidade sustentável, atendendo uma série de requisitos pré-estabelecidos. Com isso, construções certificadas LEED se beneficiam economicamente, socialmente e ambientalmente, além de reduzirem seus consumos de água em 40\%, de energia em 30\%, de emissão de CO2 em 35\% e de resíduos em $65 \%$ (GBC-BRASIL, 2014). 


\section{Metodologia}

Utilizou-se, como metodologia, a pesquisa por meio da seleção bibliográfica de artigos nas plataformas de pesquisa Google Acadêmico e Portal de Periódicos CAPES/MEC, bem como em fontes jornalísticas e técnicas da área de engenharia civil, arquitetura e ciências biológicas.

Foram incluídas as bibliografias encontradas através de buscas, com os seguintes descritores: "construções sustentáveis", "sustentabilidade na engenharia civil”, "edificações sustentáveis" e "eco construções".

Selecionou-se duas tecnologias que estão em destaques no cenário atual, sendo que todas elas estão relacionadas aos pontos-problemas apontados por Corrêa (2009), destacados no tópico anterior.

Foram exploradas as características técnicas de cada tecnologia e a viabilidade foi avaliada através dos indicadores, descritos na tabela 1. Esses indicadores foram pautados nos princípios do desenvolvimento sustentável e subdivididos em macroindicadores sociais, econômicos e ambientais, sendo que os resultados serão interpretados da seguinte forma: Total $(\mathrm{T}) \leq 1=$ pouco viável; $2 \leq \mathrm{T} \leq 7=$ moderadamente viável; $8 \leq \mathrm{T} \leq 9=$ viável.

Tabela 1 - Indicadores de viabilidade

\begin{tabular}{|c|c|c|c|c|}
\hline \multicolumn{5}{|c|}{ INDICADORES DE VIABILIDADE } \\
\hline \multirow{2}{*}{$\begin{array}{l}\text { Macro- } \\
\text { indicador }\end{array}$} & \multirow{2}{*}{ Micro-indicador } & \multicolumn{3}{|c|}{ Parâmetros } \\
\hline & & Ruim (1) & Bom (2) & Ótimo (3) \\
\hline Social & $\begin{array}{l}\text { Harmonia com o } \\
\text { ambiente entorno } \\
\text { e poluição visual }\end{array}$ & $\begin{array}{l}\text { Equipamento se } \\
\text { destaca em relação } \\
\text { ao entorno e a } \\
\text { construção } \\
\text { principal, } \\
\text { características do } \\
\text { equipamento se } \\
\text { sobressaem. }\end{array}$ & $\begin{array}{l}\text { Aparelho consegue } \\
\text { harmonizar com } \\
\text { ambiente } \\
\text { moderadamente, suas } \\
\text { características e } \\
\text { componentes } \\
\text { harmonizam, mas } \\
\text { notadamente não são } \\
\text { parte integrante da } \\
\text { construção. }\end{array}$ & $\begin{array}{c}\text { Equipamento } \\
\text { altamente } \\
\text { harmonizado com } \\
\text { o ambiente } \\
\text { entorno, } \\
\text { características são } \\
\text { integrantes a } \\
\text { construção. }\end{array}$ \\
\hline Econômico & $\begin{array}{l}\text { Acessibilidade } \\
\text { financeira }\end{array}$ & $\begin{array}{c}\text { Equipamento } \\
\text { acessível a classes } \\
\text { mais altas }\end{array}$ & $\begin{array}{l}\text { Equipamento acessível } \\
\text { a classe média e alta }\end{array}$ & $\begin{array}{c}\text { Equipamento } \\
\text { acessível a } \\
\text { quaisquer classes }\end{array}$ \\
\hline
\end{tabular}




\begin{tabular}{|c|c|c|c|c|}
\hline \multirow{4}{*}{ Ambiental } & $\begin{array}{c}\text { Relevância } \\
\text { ambiental (nível } \\
\text { de impacto } \\
\text { ambiental da } \\
\text { fonte a qual } \\
\text { substituí, status de } \\
\text { conservação da } \\
\text { fonte que } \\
\text { preserva) }\end{array}$ & $\begin{array}{c}\text { Pouca ou nenhuma } \\
\text { relevância } \\
\text { ambiental }\end{array}$ & $\begin{array}{c}\text { Relevância ambiental } \\
\text { moderada }\end{array}$ & $\begin{array}{c}\text { Alta relevância } \\
\text { ambiental }\end{array}$ \\
& & & & \\
\hline
\end{tabular}

Fonte: o autor (2018).

\section{Resultados e discussões}

\subsection{Energia fotovoltaica (Sistemas on grid)}

De acordo com o Anuário Estatístico de Energia Elétrica de 2018 (EPE, 2018) o consumo de energia elétrica no Brasil está aumentando nos setores comercial, rural e residencial, em contrapartida no setor industrial, responsável por 33\% do consumo total no ano de 2017 (EPE, 2018 b.), este número está decaindo (tabela 2) graças a busca das empresas pela redução de seus gastos e comprometimento com o desenvolvimento sustentável.

Tabela 2 - Consumo energético no Brasil por setor (2013-2017) (GWh)

\begin{tabular}{|c|c|c|c|c|c|c|}
\hline SETOR/ ANO & $\mathbf{2 0 1 3}$ & $\mathbf{2 0 1 4}$ & $\mathbf{2 0 1 5}$ & $\mathbf{2 0 1 6}$ & $\mathbf{2 0 1 7}$ & $\begin{array}{c}\text { Aumento } \\
(\boldsymbol{\%})\end{array}$ \\
\hline RESIDENCIAL & 124908 & 132302 & 131190 & 132872 & 134369 & $\mathbf{7 , 5 7 \%}$ \\
\hline INDUSTRIAL & 184685 & 179106 & 169289 & 165314 & 167398 & $-9,36 \%$ \\
\hline COMERCIAL & 83704 & 89840 & 90768 & 87873 & 88292 & $\mathbf{5 , 4 8 \%}$ \\
\hline RURAL & 23455 & 25671 & 25899 & 27266 & 28136 & $\mathbf{1 9 , 9 6 \%}$ \\
\hline
\end{tabular}

Fonte: Dados EPE (2018).

Consoante a isto, a International Energy Agency (IEA) estimou que em 2003 um terço da energia consumida em países mais desenvolvidos é destinado ao arrefecimento, aquecimento, iluminação, equipamentos e operações gerais em edifícios não industriais (IEA, 2004).

Mateus (2009) estimou que em 2005 o setor doméstico representou um peso de $17 \%$ no total de energia disponível para consumo, cujo uso seria repartido em $50 \%$ para aquecimento de água para o uso sanitário, 25\% para iluminação e alimentação de equipamentos e $25 \%$ para aquecimento/arrefecimento do ambiente interno (MATEUS, 2009). 
No Brasil, o consumo de energia elétrica por residências representa 9,7\% do consumo total, e 4,3\% do total de emissões antrópicas associadas à matriz energética brasileira (EPE, 2018 b). Esse consumo é atendido em 90\% por hidrelétricas e termoelétricas que predominam na matriz energética nacional (EPE, 2018 b.).

Referente às hidrelétricas, Bortoleto (2001) confirma os efeitos positivos dessas usinas para o desenvolvimento regional, porém destaca que dada a ineficiência do Estado em elaborar e aplicar políticas integradas, os impactos negativos acabam sobressaindo em relação aos pontos positivos destes projetos.

Em relação às termoelétricas, pode-se destacar os impactos relacionados às emissões de gás carbônico, óxidos de nitrogênio e enxofre, importantes poluentes que acentuam o efeito estufa e acarretam chuvas ácidas (FAVARETTO, 1999 apud. INATOMI; UDAETA, 2005).

O Brasil protagonizava em 2015 o sétimo lugar na lista de países que mais geram energia por meio de fontes alternativas (EPE, 2018 a.). Entretanto, um estudo realizado em 2016 pelo Instituto de Desenvolvimento Estratégico do Setor Energético (ILUMINA, 2016) constatou que o país, dentre os 23 pesquisados, é onde o consumidor - que ganha um salário mínimo - tem que trabalhar o maior número de horas para pagar sua conta de energia (11,1 horas). Guadagnin (2016) discorre sobre um levantamento realizado pelo Dr. Delberis Lima (PUC-RIO) que constata que a conta de luz do brasileiro representava $17 \%$ do salário-mínimo do trabalhador à época.

Portanto, diante dos pontos expostos, nota-se a necessidade de se investir e aplicar tecnologias voltadas para a geração de energia por meio de fontes renováveis, para mitigar os impactos ambientais intrínsecos à geração de energia, bem como proporcionar economia ao consumidor.

A energia fotovoltaica surge como opção e consiste na conversão direta da radiação solar em energia elétrica, a partir da incidência da luz do sol sobre as células fotovoltaicas. Essas células em conjunto formam os módulos solares (painéis) e essa conversão ocorre por meio do fenômeno conhecido como efeito fotovoltaico (SILVA, 2015).

Das tecnologias existentes, destaca-se o painel rígido de silício cristalino que, segundo Silva (2015) e Esposito e Fuchs (2013), domina o mercado atual e representa 80\% das vendas entre as tecnologias de painéis fotovoltaicos.

Estes sistemas consistem em conjuntos de módulos solares e são classificados de acordo com a geração, entrega e armazenamento da energia elétrica obtida. Esses sistemas são classificados em sistemas on grid e off grid; primeiro se caracteriza por ser conectado à 
rede de transmissão e o segundo por necessitar de baterias para armazenar a energia obtida (BOSO; GABRIEL; GABRIEL FILHO, 2015).

Os painéis solares geram energia por corrente elétrica contínua e deve ser convertida em corrente alternada — corrente utilizada pelos aparelhos residenciais. Essa conversão é realizada através do inversor, sendo esse inversor e os painéis os principais componentes do sistema fotovoltaico (BOSO; GABRIEL; GABRIEL FILHO, 2015).

Uma vez que não há armazenamento da energia gerada por meio de baterias, é frequente o questionamento de como haverá energia elétrica em períodos de ausência da luz solar; assim, a Agência Nacional de Energia Elétrica (ANEEL) estabeleceu, em sua resolução normativa $n^{\circ}$ 482/12 (art. $2^{\circ}$ ), o sistema de compensação de energia elétrica (ANEEL, 2012).

Esta resolução é um ponto positivo sobre o uso da tecnologia, uma vez que permite que a energia gerada seja injetada diretamente na rede, a título de empréstimo gratuito compensado na forma de consumo de energia elétrica da distribuidora (SILVA, 2015).

O excedente da relação geração/consumo é acumulado em forma de crédito e pode ser utilizado em momentos sem nenhuma ou pouca geração de energia (à noite ou em dias nublados) ou para abatimento da fatura energética de outros imóveis (autoconsumo remoto) (LIMA, 2018).

A energia fotovoltaica possui elevada dependência climática, o que seria tecnicamente um ponto negativo a ser considerado; porém, ressalta-se que no Brasil o potencial fotovoltaico era pouco mais de 2 vezes maior que o consumo residencial de energia elétrica em 2013 (EPE, 2014), sendo que todas as regiões do país recebem quantidades consideráveis de radiação solar e, consequentemente, possuem significativo potencial fotovoltaico em relação ao consumo residencial.

Apesar das diferenças climáticas no Brasil, Pereira et al (2006) afirmam que a média anual de irradiação global é uniforme e relativamente alta em todo país (Figura 1). 
Figura 1 - Média anual do total diário de irradiação solar global incidente no território brasileiro.

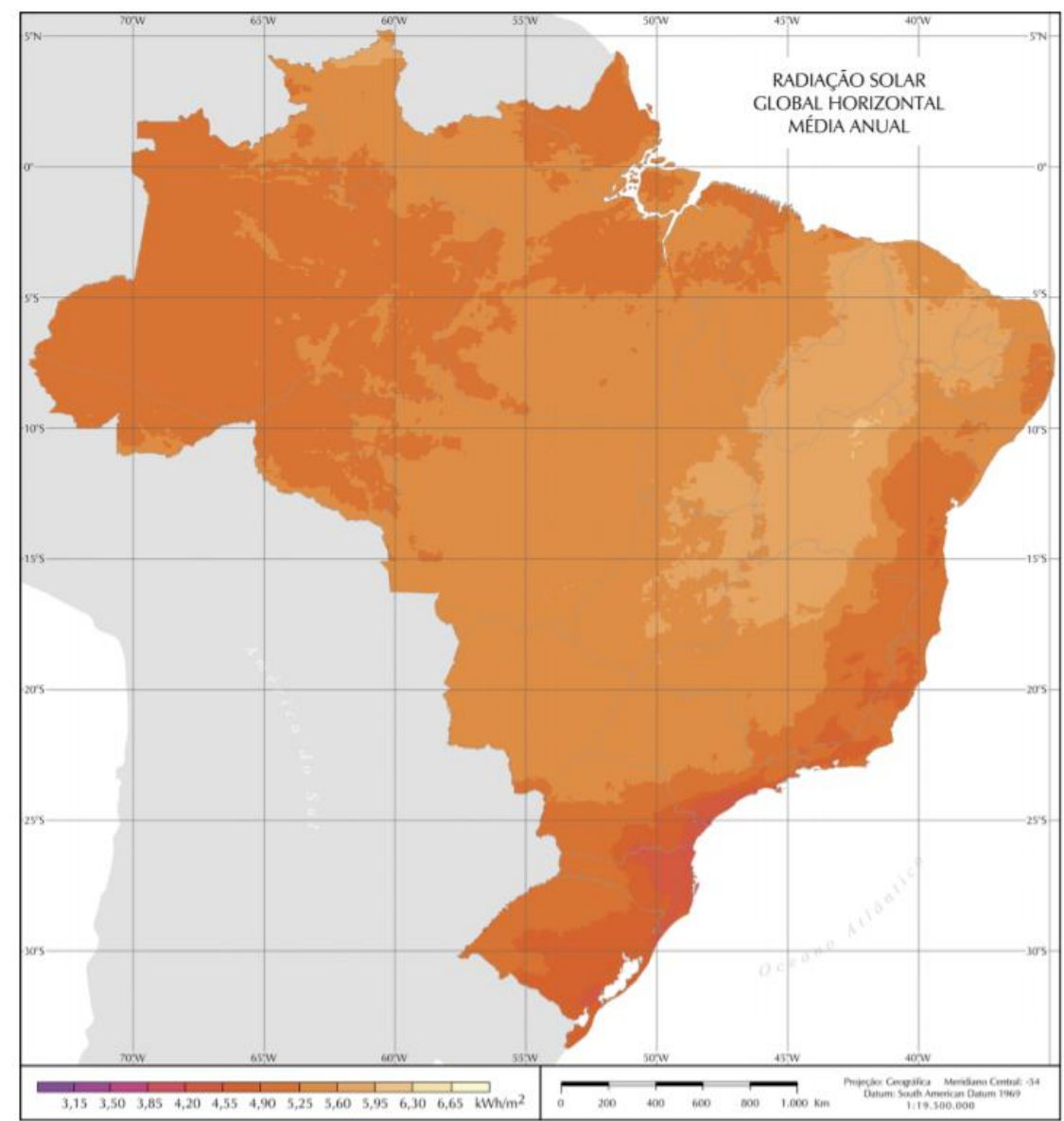

Fonte: Pereira et al (2006).

Em consonância, o Atlas Brasileiro da Energia Solar aponta que os valores de irradiação solar global incidente em qualquer região do território brasileiro (1500-2500 kWh/m2) são superiores aos da maioria dos países da União Europeia, como Alemanha (900-1250 kWh/m2), França (900-1650kWh/m2) e Espanha (1200-1850 kWh/m2) (PEREIRA et al 2006).

Expostos os pontos e alguns questionamentos comuns sobre o uso da energia fotovoltaica, a viabilidade da instalação desta tecnologia será avaliada a partir da análise dos indicadores relacionados anteriormente.

Em relação ao indicador social, de harmonia com o ambiente entorno e poluição visual, considerou-se que os módulos solares geralmente não criam harmonia com o conjunto, podendo causar um impacto visual negativo e desvalorização da arquitetura (SUSTENTARQUI, 2014), sendo então atribuído nota 1 a este indicador.

Em relação ao indicador econômico, foram realizados dois orçamentos, considerando o gasto médio de $370 \mathrm{KWh} /$ mês (Tabela 3 ). 
Tabela 3 - Orçamentos realizados em empresas do estado do RJ, levando em consideração um consumo mensal médio de $370 \mathrm{KWh}$.

\begin{tabular}{|c|c|c|c|c|}
\hline FORNECEDOR & $\begin{array}{c}\text { GERAÇÃO } \\
\text { ESTIMADA } \\
\text { /MÊS }\end{array}$ & $\begin{array}{c}\text { ECONOMIA } \\
\text { ESTIMADA/ANO }\end{array}$ & $\begin{array}{c}\text { PAYBACK } \\
\text { ESTIMADO }\end{array}$ & $\begin{array}{c}\text { VALOR DA } \\
\text { PROPOSTA }\end{array}$ \\
\hline 1 & $275 \mathrm{KWh}$ & $\mathrm{R} \$ 3.297,04$ & 5 anos & $\mathrm{R} \$ 17.753,80$ \\
\hline 2 & $226 \mathrm{KWh}$ & $\mathrm{R} \$ 2.472,65$ & 5,8 anos & $\mathrm{R} \$ 15.253,07$ \\
\hline
\end{tabular}

Fonte: Autor (2018).

O preço de aquisição destes sistemas geralmente é considerado um ponto negativo, conforme visto em Pereira et al (2014), porém por mais que o investimento possa parecer alto, vale ressaltar que dos orçamentos supracitados, os fornecedores propuseram financiamento de 36 a 60 meses — o que viabilizaria o pagamento.

Esta flexibilização, combinada com a isenção de alguns impostos para venda e importação de produtos específicos, além da redução de tarifas expostas por Silva (2015, p.8), permite o acesso de outras classes econômicas a essa tecnologia, o que atribui ao sistema fotovoltaico nota 2 no tocante ao indicador econômico.

Em relação à relevância ambiental, a redução do uso de fontes energéticas não sustentáveis, possibilitada a partir da obtenção de energia pelo meio solar, reduz consideravelmente a emissão de gases do efeito estufa da atmosfera, como visto na proposta do segundo fornecedor. Nessa proposta, é descrito que a geração de energia elétrica por meio de seus painéis, devido a não utilização das fontes tradicionais, proporcionaria a retirada de aproximadamente $87 \mathrm{kgCO} 2 / \mathrm{ano}$ da atmosfera - o que equivale a 13 árvores plantadas.

Atribuiu-se ao sistema nota 3 no que se refere ao indicador ambiental no quesito redução dos gases do efeito estufa - já que esses gases são um dos maiores problemas ambientais do planeta.

Sendo assim, a partir da soma das notas (Total $=6$ ), considera-se a energia fotovoltaica moderadamente viável.

\subsection{Telhado verde}

A impermeabilização do solo é outro problema relacionado à expansão urbana, o que ocasiona ilhas de calor e enchentes - um grande problema atual dos centros urbanos brasileiros. Assim, a arborização urbana surge como uma das soluções para mitigar esses 
problemas, visto que, além da função paisagística, proporciona a purificação do ar, melhoria do microclima da cidade, entre outros benefícios (RIBEIRO, 2009).

Do ponto de vista da propriedade privada, o espaço disposto para arborização geralmente é reduzido; desta forma, surge como solução o uso de áreas antes inutilizadas, como por exemplo, telhados e lajes.

Telhado verde ou green roof consiste na utilização de vegetação no fechamento do topo de edificações e residências. De acordo com Pereira et al. (2014), as coberturas verdes podem ser classificadas em duas categorias: extensivas ou intensivas. A primeira categoria consiste na aplicação de uma fina camada de substrato, seguida de plantas rasteiras ou gramíneas, criando um visual homogêneo e com menos necessidade de manutenção, como podas e rega.

Já a segunda categoria consiste na aplicação de uma camada maior de substrato, o que permite a fixação desde plantas rasteiras até algumas espécies lenhosas. Isso impede a aplicação em superfícies muito inclinadas, desenvolvendo, dessa forma, uma paisagem mais heterogênea.

Uma vez que a densidade de plantas nesta cobertura tende a ser maior, sugere-se incluir esta opção de telhado no anteprojeto da edificação, visto a necessidade de cálculos estruturais específicos (PEREIRA et al., 2014).

Apesar desta sugestão, Baldessar (2012) afirma que há a possibilidade de utilizar essa tecnologia em edificações já construídas, desde que sejam verificadas as condições e a resistência da estrutura que irá receber o telhado verde para que, caso seja necessário, haja um reforço estrutural nela.

A tecnologia do telhado verde é composta basicamente de sete camadas, são elas: pavimento do telhado, impermeabilização, barreira antiraizes, drenante, filtro, substrato e vegetação (Figura 2).

Figura 2 - Principais camadas do telhado verde

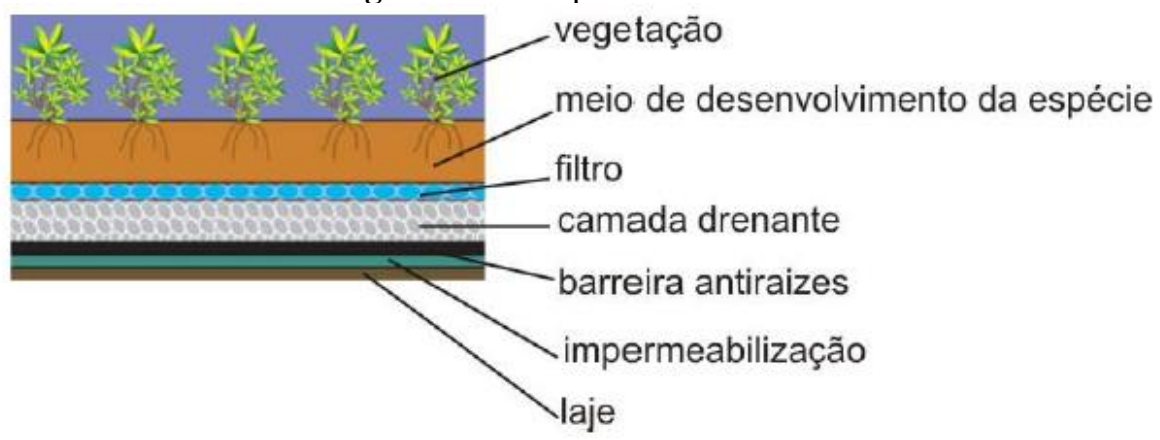

Fonte: (PEREIRA, 2014) 
Estas camadas juntas proporcionam o desenvolvimento das plantas escolhidas, bem como a manutenção da estrutura da instalação; evita-se, por exemplo, a infiltração de água através do sistema de drenagem e impermeabilização.

Baldessar (2012) aponta uma série de benefícios em relação à instalação de telhados verdes, entre eles a retenção de água das chuvas, redução das ilhas de calor urbanas, melhoria da qualidade do ar e os benefícios econômicos, através da redução do consumo de energia elétrica. Em um estudo feito por De Mello et al. (2010), estimou-se uma redução de $48,4 \%$ no consumo de energia elétrica, obtida com o arrefecimento natural proporcionado por esta tecnologia.

Para verificação da viabilidade do telhado verde, considerando-se os pontos supracitados, atribuiu-se ao macro indicador ambiental nota máxima (3). A mesma nota foi atribuída ao indicador social, já que Cantor (2008, apud. BALDESSAR, 2012) destaca a suavização visual e "recuperação" natural da área antropizada; além disso, o telhado verde vem sendo amplamente estudado e difundido por arquitetos e engenheiros.

No tocante ao indicador econômico foram orçados os materiais necessários para instalação de um telhado verde intensivo simples, em uma área com inclinação de 10 graus (para proporcionar o escoamento por gravidade da água excedente) de aproximadamente 50 m2 de laje de concreto, cujos valores estão descritos na Tabela 4.

Tabela 4 - Orçamento dos materiais para sistema simples de telhado verde

\begin{tabular}{|c|c|c|c|c|c|}
\hline CAMADA & MATERIAL & QTDE. & & $\begin{array}{l}\text { LOR } \\
\text { ÁRIO }\end{array}$ & $\begin{array}{l}\text { VALOR } \\
\text { TOTAL } \\
\end{array}$ \\
\hline Impermeabilização & $\begin{array}{l}\text { Manta asfáltica } \\
\quad(10 \mathrm{~m} 2)\end{array}$ & 5 & $\mathrm{R} \$$ & 152,91 & $\mathrm{R} \$ 764,55$ \\
\hline Filtragem & $\begin{array}{l}\text { Manta geotêxtil } \\
\qquad(50 \mathrm{~m} 2)\end{array}$ & 2 & $\mathrm{R} \$$ & 107,00 & $\mathrm{R} \$ 214,00$ \\
\hline Drenagem & $\begin{array}{l}\text { Calha galvanizada } \\
\qquad(2 \mathrm{~m})\end{array}$ & 5 & $\mathrm{R} \$$ & 23,31 & $\mathrm{R} \$ 116,55$ \\
\hline Substrato & $\begin{array}{l}\text { Argila expandida (50 } \\
\text { 1) }\end{array}$ & $100 *$ & $\mathrm{R} \$$ & 26,58 & $\mathrm{R} \$ 2.658,00$ \\
\hline \multirow[t]{2}{*}{ Vegetação } & $\begin{array}{l}\text { Grama esmeralda } \\
(\mathrm{m} 2)\end{array}$ & 50 & $\mathrm{R} \$$ & 5,90 & $\mathrm{R} \$ 295,00$ \\
\hline & & & \multicolumn{2}{|c|}{ TOTAL } & $R \$ 4.048,10$ \\
\hline
\end{tabular}

Fonte: o autor (2018).

O valor acima descrito é referente a um sistema simples, sem a incorporação de proteção antiraízes, drenos ou módulos para coleta d'água - entre outras estruturas que 
tornam o todo mais complexo e consequentemente mais caro; além disso, não se levou em consideração o preço de mão de obra.

Apesar disso, Savi (2012) comparou diversos tipos de telhado verde com métodos usuais de cobertura. Em seus resultados, destacou-se que o método mais barato encontrado foi o telhado verde vernacular, com preço de aproximadamente $\mathrm{R} \$ 182,06 / \mathrm{m} 2 \mathrm{em}$ comparação aos $\mathrm{R} \$ 249,55 / \mathrm{m} 2$ da cobertura de laje com telha de cerâmica.

Por essas razões, foi atribuído ao sistema de telhado verde nota 2 em relação ao indicador econômico, o que torna essa tecnologia viável $(\mathrm{T}=8)$.

\section{Considerações finais}

Além dos sistemas explorados por este trabalho existe um extenso leque de tecnologias que também objetivam a sustentabilidade e o cuidado com Meio Ambiente. Nessa seara, a energia solar e o telhado verde se mostraram viáveis para os indicadores selecionados, do ponto de vista do desenvolvimento sustentável — proporcionando bemestar social, economia e boa relação com o meio ambiente. Apesar disso, sugere-se que para otimizar tais pontos sejam realizadas em conjunto ações básicas, como por exemplo a reciclagem doméstica.

É compromisso do indivíduo zelar pelo meio ambiente, bem como é do Estado a responsabilidade de incentivar o uso destas alternativas por meio da diminuição da carga tributária sobre impostos e serviços, bem como disponibilizar facilidades para empresários e consumidores; desta forma, busca-se o objetivo comum do desenvolvimento sustentável.

Além disso é notório que o desenvolvimento urbano é necessidade frente à crescente demanda por moradia de uma população mundial cada vez maior; com isso, medidas mitigatórias tornam-se igualmente urgentes.

Desta maneira, não basta que as soluções apresentadas neste estudo estejam vinculadas apenas a uma pequena parcela da população, que se preocupa com o meio ambiente, e sim que sejam disponibilizadas, por exemplo, em espaço públicos e se tornem mais acessíveis para as demais classes sociais.

Apesar de o senso comum estabelecer ideias e contradições sobre os benefícios destas tecnologias, no âmbito do tripé da sustentabilidade (sócio-econômico-ambiental), percebe-se que atualmente há uma certa popularização desta cultura em prol do meio ambiente. Essas causas ambientais têm se tornado frequentes, originando uma nova geração de cidadãos, acima de tudo, consumidores, conscientes. 


\section{Referências}

ANEEL. Resolução Normativa no 482, de 17 de abril de 2012. Brasília, DF, 19 abr. 2012. v. 149, n. 76, Seção 1, p. 53. Disponível em:

http://www2.aneel.gov.br/cedoc/ren2012482.pdf. Acesso em: 29 out. 2018.

BALDESSAR, S.M.N. Telhado verde e sua contribuição na redução da vazão da água pluvial escoada. 24 f. Dissertação (Mestrado em Engenharia Civil) - Programa de PósGraduação em Engenharia de Construção Civil, Universidade Federal do Paraná, Curitiba, 2012.

BORTOLETO, E.M. A implantação de grandes hidrelétricas: desenvolvimento, discursos impactos. Geografares, n. 2, p. 53- 62, jun. 2001.

BOSO, A.C.M.R.; GABRIEL, C.P.C.; GABRIEL FILHO, L.R.A. Análise de custos dos sistemas fotovoltaicos on-grid e off-grid no Brasil. Revista Científica ANAP Brasil, v. 8, n. $12,2015$.

BRASIL. Constituição (1988). Constituição da República Federativa do Brasil. Brasília: Centro Gráfico, 1988. 292 p.

BRASIL, Estatuto da Cidade. Lei n. 10.257, de 10 de julho de 2001, que estabelece diretrizes gerais da política urbana. Brasília: Câmara dos Deputados, Coordenação de Publicações, 2001.

CANÇADO, J.E.D. et al. Repercussões clínicas da exposição à poluição atmosférica. J bras pneumol, v. 32, n. 1, p. S5-S11, 2006.

CANTOR, S.L. Green roofs in sustainable landscape design. New York: W.W. Norton \& Company, 2008.

CINEXPAN. Calculadora de argila expandida. Disponível em:

https://www.cinexpan.com.br/calculadora/calculo-ok.asp. Acesso em: 19 nov. 2018.

CORRÊA, L.R. Sustentabilidade na construção civil. Trabalho de Conclusão de Curso (Curso de Especialização em Construção Civil) - Escola de Engenharia, Universidade Federal de Minas Gerais, 2009.

DAVIS, M. Planeta Favela. São Paulo: Boitempo, 2006.

DE MELLO, G.B.P et al. Estudo da implantação de um telhado verde na Faculdade de Engenharia Mecânica. Revista Ciências do Ambiente On-Line, v. 6, n. 2, 2011.

EPE. Anuário Estatístico de Energia Elétrica. 2018 a. Disponível em:

http://www.epe.gov.br/pt/publicacoes-dados-abertos/publicacoes/anuario-estatistico-deenergia-eletrica. Acesso em: 22 out. 2018.

EPE. Balanço Energético Nacional. 2018 b. Disponível em:

http://www.epe.gov.br/pt/publicacoes-dados-abertos/publicacoes/balanco-energeticonacional-2018. Acesso em: 22 out. 2018. 
EPE. Inserção da geração fotovoltaica distribuída no Brasil-condicionantes e impactos. Nota Técnica. Rio de Janeiro: Ministério de Minas e Energia, 2014.

ESPOSITO, A.S.; FUCHS, P.G. Desenvolvimento tecnológico e inserção da energia solar no Brasil. Revista do BNDES, n.40, p. 85-114, 2013.

FAVARETTO, J.A. Biologia: uma abordagem evolutiva e ecológica. Editora Moderna. São Paulo: 1997.

GBC BRASIL. Certificação LEED. 2014. Disponível em:

http://www.gbcbrasil.org.br/sobre-certificado.php. Acesso em: 14 set. 2018.

GUADAGNIN, C. Conta de luz consome 17\% do salário mínimo do brasileiro. 2016.

Disponível em: https://www.gazetadopovo.com.br/economia/energia-e-

sustentabilidade/conta-de-luz-consome-17-do-salario-minimo-do-brasileiro-

0xb9t8f7v27y7o45zminqdcaq/\#fale-com-a-redacao. Acesso em: 25 out. 2018.

IEA. World Energy Outlook. International Energy Agency:2004. Disponível em: https://eneken.ieej.or.jp/data/pdf/951.pdf. Acesso em: 22 jul. 2020.

ILUMINA. Salário mínimo, MWh máximo. 2016. Disponível em: http://www.ilumina.org.br/salario-minimo-mwh-maximo/. Acesso em: 24 out. 2018.

INATOMI, T.A.H; UDAETA, M.E.M. Análise dos Impactos Ambientais na Produção de Energia dentro do Planejamento Integrado de Recursos. In: III WORKSHOP INTERNACIONAL BRASIL - JAPÃO: IMPLICAÇÕES REGIONAIS E GLOBAIS EM ENERGIA, MEIO AMBIENTE E DESENVOLVIMENTO SUSTENTÁVEL. 2005, Campinas. Anais[...] Campinas: Unicamp, 2005.

KIBERT, C. J. Establishing principles and a model for sustainable construction. In: Proceedings of the first international conference on sustainable construction. Tampa: University of Florida, 1994.

LIMA, Danilo de Brito. Cooperativas de energia: Guia de constituição de cooperativas de geração distribuída fotovoltaica. 2018. Disponível em:

api.somoscooperativismo.coop.br/portal/arquivopublicacao/arquivo/get/71. Acesso em: 29 out. 2018.

MATEUS, R.F.M.S. Avaliação da sustentabilidade da construção: Propostas para desenvolvimento de edifícios mais sustentáveis. 2009. 427 f. Tese (Doutorado em Engenharia Civil) - Curso de Engenharia Civil/ Processos de Construção, Escola de Engenharia, Universidade do Minho, Braga, 2009.

ONU - Organização das Nações Unidas. World Urbanization Prospects. Nova Iorque:

ONU, 2018. Disponível em: https://population.un.org/wup/Country-Profiles/. Acesso em: 20 mar. 2018.

PEREIRA, E.B. et al. Atlas brasileiro de energia solar. São José dos Campos: Inpe, 2006. 
PEREIRA, M.F.B. et al. Conteúdo energético e emissões de CO2 em coberturas verdes, de telha cerâmica e de fibrocimento: estudo de caso. 2014. Dissertação (Mestrado em Engenharia Civil) - Programa de Pós-graduação em Engenharia Civil, Universidade Federal de Santa Maria, Santa Maria, 2014.

PRIZIBISCZKI, C. O crescimento urbano é o problema do século. 2013. Disponível em: https://www.oeco.org.br/colunas/colunistas-convidados/27229-o-crescimento-urbano-e-oproblema-do-seculo/. Acesso em: 13 set. 2018.

RIBEIRO, F. A. B. S. Arborização urbana em Uberlândia: percepção da população. Revista da Católica, Uberlândia, v. 1, n. 1, p. 224-237, 2009.

SAVI, Adriane Cordoni. Telhados verdes: análise comparativa de custo com sistemas tradicionais de cobertura. 2012.Trabalho de Conclusão de Curso (Especialização em Ambiente Construído) - Programa de Pós-Graduação em Engenharia da Construção Civil, Universidade Federal do Paraná, Curitiba, 2012.

SILVA, R. M. Energia solar no Brasil: dos incentivos aos desafios. Brasília: Núcleo de Estudos e Pesquisas/CONLEG/Senado, fev. 2015. Disponível em: www.senado.leg.br/estudos. Acesso em: 25 out. 2018.

SUSTENTARQUI. Integração da energia solar elétrica na arquitetura. 2014. Disponível em: https://sustentarqui.com.br/integracao-da-energia-solar-eletrica-na-arquitetura/. Acesso em: 31 out. 2018.

VASCONCELOS, A.M.N; GOMES, M.M.F. Transição demográfica: a experiência brasileira. Epidemiologia e Serviços de Saúde, v. 21, n. 4, p. 539-548, 2012.

VICENTINO, C; DORIGO, G. História: História Geral e do Brasil. 2. ed. São Paulo: Scipione, 2007. 616 p.

VORMITTAG, E. M. A.; SALDIVA, P. H.; MIRANDA, MJ de. Avaliação do impacto da poluição atmosférica no Estado de São Paulo sob a visão da saúde. Instituto Saúde e Sustentabilidade, São Paulo, 2013. DOI: https://www.scielo.br/pdf/rbepop/v32n3/01023098-rbepop-32-03-0489.pdf. 